\title{
Alanine Aminotransferase 1
}

National Cancer Institute

\section{Source}

National Cancer Institute. Alanine Aminotransferase 1. NCI Thesaurus. Code C38507.

Alanine aminotransferase 1 (496 aa, $\sim 55 \mathrm{kDa}$ ) is encoded by the human GPT gene. This protein plays a role in both amino acid metabolism and pyruvate synthesis. 